\title{
Expectativas de Gestantes sobre o Parto e suas Percepções acerca da Preparação para o Parto
}

\author{
Natalia Almeida Tostes ${ }^{1}$ \\ Programa de Pós-Graduação em Processos de Desenvolvimento Humano e Saúde \\ da Universidade de Brasília, Brasília, DF, Brasil \\ Eliane Maria Fleury Seidl \\ Instituto de Psicologia da Universidade de Brasília, Brasília, DF, Brasil
}

\begin{abstract}
Resumo
A gestação e o parto são experiências significativas para a maior parte das mulheres. As expectativas de gestantes podem influenciar suas vivências relacionadas ao parto e à maternidade. Esta pesquisa investigou as expectativas de primigestas sobre o parto e suas percepções acerca da preparação para o parto. Trata-se de estudo qualitativo, exploratório e descritivo. Foram realizadas entrevistas com 18 mulheres no terceiro trimestre de gravidez, que faziam acompanhamento pré-natal em serviços da rede pública de Brasília (DF). Para a análise dos relatos foram utilizados procedimentos de análise de conteúdo. Como principais resultados, destacaram-se: preferência das entrevistadas por parto normal; expectativas relacionadas ao parto, em geral negativas, perpetuando ideias de um momento de medo, dor e sofrimento, podendo trazer riscos para a mulher e para o bebê; sentimentos de preparação insuficiente e falta de confiança para vivenciar o parto. Pôde-se identificar demanda por mais informações sobre temas associados à gestação, em particular o parto, bem como a necessidade de maior apoio psicoemocional às gestantes no pré-natal.
\end{abstract}

Palavras-chave: Assistência pré-natal, percepções de gestantes, parto, psicologia da saúde.

\section{Expectant Mother's Expectations for Birth and their Perceptions of Delivery and Birth Preparation}

\begin{abstract}
Pregnancy and childbirth are significant experiences for most women. Expectant mother's expectations can influence her experiences related to birth and motherhood. This study aimed to investigate first-time expectant mothers' expectations for birth and their perceptions of preparation for birth. To this end, a qualitative, exploratory, and descriptive study was conducted. Eighteen first-time expectant mothers in their third trimester of pregnancy were interviewed. The methodology to analyze the women reports consisted of content analysis. The main results were: preference for vaginal birth among most women; expectations for childbirth, in general very negative, containing ideas of fear, pain and suffering, seeing childbirth as a life-threatening moment to women and their babies; feelings reported by expectant mothers of not being sufficiently prepared and confident for experiencing birth. We were able to ascertain the need for more information during the prenatal care services about pregnancy, namely childbirth, as well as the need for greater psycho-emotional support for expectant mothers.
\end{abstract}

Keywords: Prenatal care, expectant mother's perceptions, childbirth, health psychology.

Endereço para correspondência: Condomínio Mini-Granjas do Torto, Rua F, casa 117, Brasília, DF, Brasil 70636-900. E-mail: nataliaalmeidatostes@gmail.com

Apoio: o presente manuscrito foi desenvolvido com o apoio financeiro do Conselho Nacional de Desenvolvimento Científico e Tecnológico (CNPq), mediante recebimento de bolsa de Mestrado pela primeira autora. 


\section{Expectativas de Mujeres Embarazadas sobre el Parto y sus Percepciones acerca de la Preparación para el Parto}

\section{Resumen}

El embarazo y el parto son experiencias significativas para la mayoría de las mujeres. Las expectativas de la futura madre influyen en sus experiencias relacionadas con el parto y la maternidad. Este estudio se basó en la investigación del parto en madres primerizas y sus percepciones acerca de la preparación para el parto en servicios de la red pública de Brasilia (DF). Con este fin, se llevó a cabo un estudio cualitativo, exploratorio y descriptivo. Se realizaron entrevistas a dieciocho mujeres en el tercer trimestre de embarazo. Como metodología, fueron utilizados procedimientos de análisis de contenido. Entre los resultados principales, se destacaron: preferencia por parto normal entre las entrevistadas; expectativas negativas, relacionadas con el parto, perpetuando ideas de momentos de miedo, dolor o sufrimiento; sentimientos de preparación insuficiente y falta de confianza para vivenciar el parto. Se puede percibir la necesidad de mayor información sobre temas de gestación, tanto del parto en particular, como la necesidad de un mayor apoyo psico-emocional a las futuras madres.

Palabras clave: Atención prenatal, percepciones de embarazadas, parto, psicología de la salud.

Ao longo do último século, mudanças importantes ocorreram no que se refere à gestação $\mathrm{e}$ à parturição. A gestação foi redefinida, passando de evento privado e feminino para evento público e médico (Davis-Floyd, 2003). O parto, antes exclusivo do universo feminino, passou a ser assistido por médicos, em grande maioria homens, predominantemente nos hospitais (Jones, 2008; Rattner, 2009). Com o movimento feminista internacional e as conquistas decorrentes dele, passou-se a questionar práticas relacionadas ao parto e ao nascimento (Santos-Neto, Alves, Zorzal, \& Lima, 2008).

No Brasil, a partir do ano de 1992, o Ministério da Saúde fez uma importante reorganização da atenção ao parto e ao nascimento. No ano 2000, instituiu o Programa de Humanização do Pré Natal e Nascimento, adotando as recomendações feitas pela Organização Mundial de Saúde OMS (Santos-Neto et al., 2008). De acordo com a Política Nacional de Humanização, instituída em 2003, a humanização envolve a valorização dos diferentes sujeitos participantes da produção de saúde (gestores, trabalhadores e usuários) por meio de sua autonomia e protagonismo. Além disso, pressupõe mudanças nos modelos de atenção e de gestão, que devem ter como foco as necessidades dos cidadãos e a produção de saúde (Rattner, 2009).
Para que tais mudanças se efetivem na assistência ao pré-natal, nascimento e puerpério, é necessária uma mudança de paradigma: respeito à individualidade da mulher, visão da mulher como protagonista e respeito à cultura, às crenças, aos valores e à diversidade de opiniões das gestantes e suas famílias - aspectos apontados como fundamentais para uma nova forma de atenção e cuidado (Mabuchi \& Fustinoni, 2008; Parada \& Tonete, 2008; Silva, Barbieri, \& Fustinoni, 2011).

Outras medidas mais recentes foram o Pacto Nacional pela Redução da Mortalidade Materna e Neonatal, em 2004, e a Política Nacional pelo Parto Natural e Contra as Cesáreas Desnecessárias, em 2008 (Santos-Neto et al., 2008). Esta última deve-se ao grande aumento que vem ocorrendo no número de partos cesáreos no Brasil, muito superior à taxa recomendada pela OMS, de $15 \%$ do total de partos. Segundo dados do Instituto Brasileiro de Geografia e Estatística (IBGE, 2009), em 2009 já havia um percentual de $43 \%$ dos partos feitos por cesariana, sendo a maior parte proveniente do setor privado. Essa porcentagem vem crescendo e as estimativas apontam que, ao final de 2014, cerca de 55\% dos partos ocorridos no Brasil foram feitos por cesárea, como afirmou Marleen Temmerman, ginecologista e diretora de Saúde Reprodutiva da 
OMS, em conferência feita em Genebra em abril de 2015, quando ressaltou a gravidade de haver uma "epidemia da cesárea" devido à semelhança das estatísticas brasileiras sobre esse procedimento às de epidemias mundiais (OMS, 2015).

Ainda que as medidas tomadas até agora tenham sido de suma importância, o aumento das taxas de cesáreas indica que é necessário estudar outras perspectivas dos universos da gestação e parturição que vão além das campanhas e políticas públicas de forma a compreender melhor alguns fatores envolvidos nesses contextos. Olhando pela perspectiva das mulheres, Almeida, Medeiros e Souza (2012) e Rattner (2009) sugerem haver uma cultura atual que não favorece o parto normal: gestantes se questionam sobre sua capacidade de parir; mulheres afirmam não ter tolerância à dor. Assim, a gestação e o parto - fenômenos fisiológicos, sociais e culturais - são permeados e influenciados diretamente por fatores psicológicos e emocionais (Pinheiro \& Bittar, 2013; Rodrigues \& Siqueira, 2008).

Experiências impactantes e significativas para a maior parte das mulheres, tanto as da gestação quanto as do parto, podem trazer consequências para o puerpério e mesmo influenciar concepções e vivências da maternidade (Bortoletti, 2007). O parto é o momento esperado, tendo significados que vão sendo construídos e reconstruídos dinamicamente na cultura em que se inserem as gestantes e também de acordo com as experiências vivenciadas por elas. Ao mesmo tempo, é também um momento frequentemente temido devido ao desconhecimento do que pode vir a ocorrer. A possibilidade de sentir dor e o medo decorrente disso também são aspectos proeminentes e influentes nas expectativas relacionadas ao parto (Almeida et al., 2012; Haddad \& Cecatti, 2011).

Historicamente, em diversas culturas e grupos sociais, as vivências do trabalho de parto e parto têm sido associadas a termos como agonia, provação, medo, terror, sofrimento, morte (Basso \& Monticelli, 2010). Ferrari (2010) e Rodrigues e Siqueira (2008) destacam o medo da dor durante o trabalho de parto e parto como um dos aspectos que influenciam a incidência de cesáreas, na medida em que a dor é tida como algo insuportável por muitas mulheres que - juntamente com a ideia de que o parto normal pode trazer riscos para o feto ou mesmo provocar lesões anatômicas e fisiológicas - causa grande temor. Estes autores sugerem que tais fatores podem fazer com que mulheres optem pelo parto cirúrgico, mesmo que não haja indicação obstétrica para tal procedimento. São as "cesarianas a pedido", como são denominadas por obstetras e outros profissionais da equipe de saúde (Pinheiro \& Bittar, 2013). É importante destacar, no entanto, que a literatura aponta que profissionais de saúde são os principais indutores à escolha da via de parto cirúrgico por mulheres gestantes (Haddad \& Cecatti, 2011).

As expectativas geradas em relação ao momento do parto geralmente são baseadas em experiências anteriores, em informações obtidas por meio de conversas com pessoas leigas, reportagens da mídia e materiais informativos e em seu background cultural (Dias \& Deslandes, 2006). Em relação à dor, há evidências de que a ansiedade e o medo em níveis moderados e altos podem aumentá-la significativamente ao longo do processo de parturição. Sua presença ou o temor de senti-la podem se juntar a uma série de sentimentos, sensações e pensamentos que são, ao mesmo tempo, mobilizados pelo mal-estar, mas também mobilizadores deste (Rodrigues \& Siqueira, 2008).

Chama-se a atenção para o fato de que a dor não é uma manifestação universal de processos orgânicos: ela se relaciona com a subjetividade de cada sujeito e com a forma como é construída pela cultura (Teixeira \& Pereira, 2006). Mais do que um processo fisiológico, trata-se de uma construção simbólica. No entanto, a biomedicina não compartilha desse olhar, pois privilegia as manifestações orgânicas, universais e quantificáveis (Tornquist, 2003). Esse fato é particularmente ilustrado no momento do parto, quando profissionais da equipe de saúde muitas vezes desconsideram as subjetividades das parturientes e as diferentes formas de vivenciar os processos de trabalho de parto e parto e expressam expectativas de que essas mulheres tenham "bons comportamentos" frente à dor: não gritar, não se desesperar, obedecer às ordens e acatar 
os conselhos da equipe, sob pena de não serem atendidas ou serem submetidas a diferentes tipos de violência, caso se "comportem mal" (Pinheiro \& Bittar, 2013). Nagahama e Santiago (2008) e Tornquist (2003) ressaltam que uma escuta acolhedora das mulheres parturientes frente às inseguranças ou à dor por parte dos profissionais que as assistem - e o respeito às diferentes formas de vivência e de expressão - são pontos muito importantes de uma atenção humanizada e de qualidade, devendo ser priorizadas nas formações dos profissionais de saúde.

Outro aspecto recorrente nas expectativas sobre o parto é o medo. O medo nem sempre se refere à dor, sendo também associado pelas parturientes ao receio da própria morte ou da morte do bebê durante o trabalho de parto. Outros medos comumente relatados referem-se a algum tipo de dano ou agravo ao bebê - como má formação ou disfunções - ou de danos ao próprio corpo (Parada \& Tonete, 2008). Assim, a dor, o medo, a ansiedade e outros fatores psicológicos podem, por vezes, ter efeitos estressantes e desgastantes sobre a vivência de parturição da mulher.

A assistência pré-natal que atende as gestantes somente em sua dimensão fisiológica, portanto, provê atenção apenas parcial às necessidades de mulheres grávidas, deixando-as desassistidas em relação a outras dimensões. Considera-se imprescindível entender melhor os aspectos sociais, psicológicos e emocionais que podem influenciar as expectativas sobre o parto, a preparação para esse momento ao longo da gestação e as vivências da parturição pelas mulheres. Por meio de um melhor entendimento desses fatores é possível contribuir para o aprimoramento dos serviços de assistência pré-natal de forma a aproximá-los das necessidades integrais das gestantes e das recomendações do Programa de Humanização do Pré-natal e Nascimento - PHPN (Ministério da Saúde, 2000), do Ministério da Saúde $(2001,2006)$ e da World Health Organization $(1985,1996)$ que - embora já existam há bastante tempo, 30 anos desde as primeiras recomendações da OMS e 15 anos desde o lançamento do PHPN - ainda estão parcialmente implantadas. Dessa forma, a presente pesquisa investigou expectativas de gestantes primigestas em relação ao parto e suas percepções acerca da assistência pré-natal relativas à preparação para o parto.

\section{Método}

Este é um estudo qualitativo, descritivo e exploratório, realizado mediante entrevistas com gestantes. A pesquisa foi realizada em dois centros de saúde da Secretaria de Estado da Saúde do Distrito Federal, localizados no Plano Piloto, em Brasília, que ofertavam atendimento pré-natal. Os serviços da rede pública de saúde foram escolhidos por atender a maior parte das gestantes do Distrito Federal, além de seguir recomendações e protocolos específicos para o atendimento no pré-natal, parto e pós-parto.

\section{Participantes}

As gestantes foram selecionadas por conveniência, com base nos seguintes critérios de inclusão: aceitar participar do estudo e assinar o termo de consentimento livre e esclarecido (TCLE); estar na primeira gravidez (ser primigesta) e não ter histórico de abortamento anterior; ser maior de idade; ter, no mínimo, 28 semanas de gestação ou sete meses completos; estar fazendo acompanhamento pré-natal na instituição em que a entrevista se realizava (mesmo que houvesse acompanhamento complementar em outro estabelecimento paralelamente ao do centro de saúde). Foram critérios de exclusão: ter gravidez de alto risco; ter doenças ou complicações graves de saúde.

Participaram do estudo 18 gestantes, sendo que dez faziam pré-natal no Centro de Saúde A e oito faziam pré-natal no Centro de Saúde B. As entrevistadas eram, em sua maioria, jovens: a média de idade foi de 24 anos, variando de 18 a 40 anos, com um desvio padrão de 5,5. Todas estavam no terceiro trimestre de gravidez, em acordo com os critérios de inclusão. A idade gestacional média foi de 35 semanas, sendo a idade mínima de 28 e a máxima de 39 semanas e dois dias, com desvio padrão de 3,3 semanas.

Quinze gestantes eram casadas $(n=8)$ ou viviam em união consensual $(n=7)$ e três se decla- 
raram solteiras. Quanto à escolaridade, a maioria tinha o ensino médio completo $(n=9)$, seguido por ensino superior incompleto $(n=5)$, ensino superior completo $(n=2)$, ensino médio incompleto $(n=1)$ e ensino fundamental completo $(n=1)$. Nota-se, portanto, que dezesseis participantes tinham nível de escolaridade elevado. As entrevistadas foram nomeadas de P1 (Participante 1) a P18 (Participante 18).

\section{Instrumentos}

Foi desenvolvido roteiro para entrevista semiestruturada com cinco questões abertas que tratavam de temas da gestação, do pré-natal e do parto, tais como: o parto como tema no pré-natal (que investigava se até o momento da entrevista as gestantes já haviam conversado com seu/sua obstetra sobre o assunto parto); expectativas sobre o parto; preferência pela via de parto; percepção sobre estar preparada para o parto; sugestões para aprimoramento do atendimento pré-natal.

$\mathrm{O}$ roteiro foi testado em estudo piloto com cinco gestantes com o objetivo de avaliar sua adequação como instrumento de coleta de dados, verificando pontos a serem adaptados ou corrigidos, e fornecer à entrevistadora oportunidades para praticar os procedimentos estabelecidos para a coleta. As entrevistas do estudo piloto não foram incluídas no conjunto analisado, tampouco discutidas nessa pesquisa.

\section{Procedimentos}

Após a aprovação do projeto no Comitê de Ética em Pesquisa da Secretaria de Estado da Saúde do Distrito Federal (Protocolo 146/2011), iniciaram-se os procedimentos de coleta de dados.

As participantes da pesquisa eram contatadas nas próprias unidades de saúde em que faziam acompanhamento pré-natal, enquanto aguardavam a consulta com obstetra. Depois da verificação de que preenchiam os critérios estabelecidos, as gestantes eram convidadas a participar. Após a assinatura do TCLE, era iniciada a entrevista. As entrevistas foram conduzidas de forma individual e ocorreram em consultórios e salas cedidos pelas unidades de saúde e que não estavam em uso no momento. Em média, as entrevistas duraram 29 minutos, tendo 43 minutos de duração a mais longa e 15 minutos a mais curta. Utilizou-se gravador de áudio durante as entrevistas, com o consentimento das participantes.

\section{Análise de Dados}

Para a análise, as entrevistas foram transcritas na íntegra. Utilizou-se os procedimentos de análise de conteúdo segundo Bardin (2011), que envolveram, em um primeiro momento, a leitura flutuante das entrevistas para a definição de eixos temáticos e, em um segundo momento, a leitura horizontal das questões, de forma a identificar as categorias para cada eixo. Os cinco eixos temáticos foram norteados em grande parte pelo próprio roteiro de entrevista, sendo os seguintes: (a) parto como tema no atendimento pré-natal; (b) preferência por via de parto; (c) expectativas para o momento do parto; (d) sentimentos de preparo e confiança para o parto; (e) contribuições do serviço na preparação da gestante para o parto. Cada eixo temático permitiu a identificação de categorias que estão apresentadas na seção Resultados e Discussão.

Os relatos das gestantes foram analisados e categorizados por meio do seu conteúdo por duas pesquisadoras de modo independente. As pesquisadoras tomaram por base a concordância de suas análises para a identificação, nomeação e frequência das categorias. Como exemplos das categorias, foram selecionados trechos de relatos das participantes do estudo.

\section{Resultados e Discussão}

Nesta seção, os cinco eixos temáticos anteriormente citados são apresentados com as respectivas categorias identificadas e exemplos de relatos ilustrativos das mesmas.

\section{O Parto como Tema no Pré-Natal}

Esse eixo investigou se, ao longo do pré-natal (até o momento da entrevista), as gestantes já haviam conversado com profissionais médicos que as atenderam sobre o parto e, em caso 
afirmativo, o que tinha sido abordado. Com base nos relatos das participantes, três categorias foram identificadas: até agora não conversamos; sim, mas foi superficial; sim e foi suficiente.

A categoria denominada até agora não conversamos teve menções de 13 entrevistadas, na qual foram incluídos relatos que referiram que o assunto do parto não tinha sido abordado nem uma vez em consultas com o profissional de medicina: "Não conversei ainda. Não sei se vai ser normal ou cesariana ... Eu sei que não sou mais nenhuma garotinha, mas já que sou mãe de primeira viagem, tem que saber de tudo, né?" (P18). Cinco delas relataram estar apreensivas pela falta de informação, já que estavam no final da gestação e próximas à vivência do parto. Duas participantes mencionaram não sentir falta de abordar esse assunto, preferindo deixar para lidar com a situação em momento mais próximo à hora do parto.

A segunda categoria - sim, mas foi superficial - obteve quatro relatos. Nestes, as gestantes afirmaram que houve alguma conversa sobre o tema em consultas individuais, mas não tiveram esclarecimentos e informação suficientes, sugerindo que o tema foi tratado de modo superficial: "Assim, não explicou detalhadamente, né, mas me deu uma noção, mais ou menos, como é. E eu tenho, assim, conversado muito com essas meninas grávidas também, que vem fazer o pré-natal comigo, então... isso também ajuda!" (P10). A terceira categoria denominada sim e foi suficiente teve menção de uma participante. Essa gestante relatou que conversou com a obstetra e recebeu as informações que necessitava: "Ela falou como é que vai ser e como é que eu ia sentir, essas coisas" (P3).

Pôde-se notar que a maior parte das gestantes (13 mulheres) relatou não ter tido conversas sobre parto na consulta médica até o momento da entrevista, resultado preocupante visto que as gestantes já estavam no terceiro trimestre da gravidez - portanto próximas do parto - sendo que algumas estavam a menos de uma semana da data prevista para o parto. Situação similar foi observada em outro estudo, como o de Domingues, Santos e Leal (2004), em que apenas 23\% das mulheres sentiam-se satisfatoriamente infor- madas sobre o que aconteceria com elas e o bebê durante o parto, $43 \%$ não se consideravam informadas e $35 \%$ sentiam-se apenas parcialmente informadas sobre o parto. Ressalta-se que a obtenção de informações adequadas, bem como o esclarecimento de dúvidas e a escuta qualificada dos anseios relativos ao trabalho de parto e ao parto são fatores que costumam favorecer as vivências desses momentos (Rodrigues \& Siqueira, 2008; Vieira, Bock, Zocche, \& Pessota, 2011). Nessa perspectiva, Rattner (2005) reitera que parturientes informadas e esclarecidas sobre o processo de parturição tendem a ficar menos ansiosas, ter interações mais harmoniosas e colaborativas com os profissionais de saúde, chorar e gritar menos durante o trabalho de parto, e geralmente têm processo de parto mais ameno e gratificante.

Outro dado de destaque no presente estudo foi a predominância da obtenção de informações sobre o parto em intervenções em grupo. Dezesseis gestantes referiram, em algum momento da entrevista, sobre palestras como a principal fonte de informação e esclarecimento de dúvidas no pré-natal das unidades de saúde pesquisadas. Por um lado, deve-se reconhecer o valor positivo dessas ações, vez que são práticas educativas importantes e promovem momentos coletivos entre as gestantes e os profissionais de saúde. No entanto, essas ações devem ter cunho complementar e não substituir os diálogos e esclarecimentos nas consultas individuais, que se constituem em espaços que permitem abordar aspectos subjetivos e específicos de cada mulher em acompanhamento. Mabuchi e Fustinoni (2008) afirmam que muitas instituições têm generalizado atendimentos que deveriam ser individualizados, tomando por base apenas o cumprimento de normas e diretrizes, visando à conquista de prêmios e gratificações, mas não consideram apropriadamente a vivência das gestantes.

\section{Preferência pela Via de Parto}

Esse eixo temático tratou das preferências das gestantes acerca da via de parto (vaginal ou cesárea) ou tipo de parto (normal ou cirúrgico). Das 18 entrevistadas, três não relataram preferência. Duas categorias foram identificadas: pre- 
ferência por parto vaginal/normal e preferência por parto cesáreo/cirúrgico. A categoria preferência por parto vaginal/normal teve relatos de 12 mulheres. As gestantes que falaram de sua preferência por esse tipo de parto alegaram como motivo principal de sua escolha o pós-parto mais tranquilo, de recuperação mais rápida. Outras razões para a preferência foram: a ideia de que é mais saudável para o bebê e sem riscos; é mais fácil; medo do parto cesáreo, que corta, deixa cicatriz e pode ser arriscado; visão do parto normal como algo para o qual o corpo da mulher já está preparado. O relato de $\mathrm{P} 7$ é ilustrativo dessa categoria:

Sempre quis ter parto normal. Graças a Deus tá tudo tranquilo pra que seja parto normal, porque eu acho que é o certo. Acho que o corpo da mulher sempre foi preparado pra isso. É claro que eu sempre tive a consciência de que, se não desse alguma coisa certa, eu ia ter que fazer uma cesárea, mas nunca foi minha preferência. . . . É, porque eu acho que é mais tranquilo o depois, no pós parto, né? Tem o risco da operação... Então eu quero dar os primeiros cuidados pro meu neném, eu quero dar banho, eu quero segurar... E muitas das mulheres que têm parto cesáreo não têm essas condições, né? (P7)

A segunda categoria - preferência por parto cesáreo/cirúrgico - teve a menção de três gestantes. As entrevistadas alegaram como principais razões de sua escolha: o medo da dor do parto normal; a tranquilidade que a previsão do nascimento traz (se for cesárea eletiva); a sensação de segurança devido ao maior controle, a partir da ideia de que há menos chances de complicações.

É porque eu não queria sentir dor, na verdade. . . Me falaram pra fazer parto normal, mas parece que a dor... Não existe outra dor do que parto normal . . . Todos dizem que é tolerável, mas não quero arriscar não. Vou fazer cesárea. É porque é mais tranquilo também, né? Pode marcar e fazer. . . Mais segurança mesmo. Porque aí já vai estar... já tá marcado, você já chega lá e faz o parto. Não precisa ficar esperando a dor chegar. Entendeu? Ou algum tipo de complicação (P15)

Em relação ao tipo de parto, destaca-se a preferência pelo parto normal/vaginal entre as participantes: a chamada "cultura da cesárea", a qual Rattner (2009) sugeriu influenciar fortemente as mulheres, não se manifestou de maneira proeminente entre as gestantes desse estudo. O predomínio da preferência pelo parto normal/ vaginal entre as participantes corrobora achados de outras pesquisas, as quais relataram que grande parte das gestantes tinha preferência pelo parto normal (Almeida et al., 2012). No entanto, ao longo do pré-natal, parte dessas gestantes parece mudar sua decisão, passando a entender que a via cesárea - apesar de muitas vezes não ser a sua preferência inicial - seria mais adequada para o nascimento do bebê. Essa mudança de escolha tem sido apontada em diferentes estudos como consequência da influência dos profissionais de saúde, particularmente os obstetras. Assim, ao longo do pré-natal, esses profissionais parecem apontar diferentes aspectos das circunstâncias fisiológicas da mulher ou do bebê que levam a indicar a cesárea como uma via mais segura ou adequada para o nascimento do bebê - apesar de grande parte delas não serem, de fato, indicação para cesarianas, de acordo com os estudos de medicina baseados em evidências (Basso \& Monticelli, 2010; Haddad \& Cecatti, 2011; Hodnett, Gates, Hofmeyr, \& Skala, 2007; Nascimento, 2011).

Os relatos da categoria preferência por parto cesáreo/cirúrgico, no entanto, vão ao encontro de outras pesquisas, em que mulheres deram preferência para o parto cesáreo por medo da dor do parto normal e pela conveniência, previsão e controle do momento do nascimento (Seibert, Gomes, \& Vargens, 2008; Teixeira \& Pereira, 2006).

As mulheres que manifestaram preferência pelo parto vaginal/normal destacaram como uma das principais vantagens a recuperação mais rápida no pós-parto (Pinheiro \& Bittar, 2013). No entanto, há diversas vantagens do parto normal (particularmente se comparada à cesárea eletiva), não só para a mãe como para o bebê (Odent, 2002). Essas vantagens não foram citadas pelas 
gestantes, indicando que pode estar havendo falhas na transmissão e divulgação de informações importantes - tanto por parte do serviço de pré-natal, quanto numa perspectiva mais ampla, por parte das campanhas e políticas de incentivo ao parto normal -, que frequentemente se atém a ressaltar a recuperação mais rápida no pós-parto.

\section{Expectativas para o Momento do Parto}

Esse eixo temático se referiu ao que vinha à mente das gestantes, o que pensavam e sentiam quando imaginavam o momento do parto. Em geral, cada gestante referiu mais de um tipo de expectativa. Somente uma entrevistada não relatou expectativas sobre o parto. As expectativas relatadas foram organizadas em quatro categorias: parto como momento de dor, mal estar e sofrimento; parto como momento entre a vida e a morte; parto como um assunto gerador de insegurança e ansiedade e parto como um momento de felicidade.

A categoria parto como momento de dor, mal estar e sofrimento, com menções de nove entrevistadas, teve referências ao parto com dor (ou medo de sentir dor), mal estar, sacrifício, sofrimento, um momento desagradável, mas pelo qual é inevitável passar. Especificamente em relação à dor, três dessas entrevistadas mencionaram expectativas de que não conseguiriam suportá-la: "Eu tenho medo da dor, porque dizem que dói muito. Às vezes eu tenho medo de que 'ai meu Deus eu não vou conseguir'..." (P13).

Uma segunda categoria foi parto como momento entre a vida e a morte, com 10 menções, com expectativas acerca do parto como um momento de risco, com possibilidades de complicações para a saúde da mãe ou do bebê, ou mesmo ocorrência de morte: "É medo do nascimento também, lá no hospital... Não sei, ninguém sabe se dá alguma coisa errada também... Eu tenho medo disso" (P14); "Tenho um medo de morrer na hora. ... É porque a gente assiste muita televisão e vê tanta coisa acontecendo, aí eu fico com medo" (P12).

No que se refere aos receios citados nesta categoria, houve destaque para a possibilidade de haver necessidade de parto cesáreo, expectativa que gerava preocupações sobre possíveis complicações decorrentes do procedimento cirúrgico, como o fato de serem cortadas, de ficarem com cicatriz, com chances de um pós-parto mais difícil. O relato de P5 é ilustrativo: "Sei lá, [medo] de não ser normal, de ser cesáreo. . . . [Ao ser perguntada se tem medo da cirurgia:] $E$ por que corta, né? Fica a cicatriz, sei lá".

A terceira categoria - parto como um assunto gerador de insegurança e ansiedade - agregou relatos de seis participantes acerca do parto como um momento de situações imprevisíveis e, por vezes, desagradáveis, gerando preocupação, ansiedade e insegurança. Duas gestantes relataram que se questionavam sobre sua capacidade de parir (via parto normal), já que tinham ouvido relatos de mulheres que não conseguiram. Alguns dos motivos citados como causa dessa "incapacidade" foi a intensidade de dor, percebida por gestantes como insuportável, bem como a dilatação insuficiente:

Porque muitas mulheres, muitas vezes, não têm contração, não têm dilatação, nem nada. Eu tô esperando por esse momento aí: de vir as dores... e eu correr pro hospital e, se Deus quiser, ter parto normal... que muitas mulheres não conseguem. (P1)

Nessa categoria duas gestantes descreveram expectativas sobre o parto como um momento de exposição, em que poderiam estar sujeitas a maus tratos por parte de profissionais de saúde e não terem sua privacidade e seu corpo respeitados. Essa possibilidade as deixava com medo e vergonha, como exemplificou P9: "E diz que tem um negócio que você fica lá e toda hora chega um estagiário e fica te enfiando o dedo ... porque, ai meu Deus do céu, eu sou muito envergonhada! Muito envergonhada!".

Outros dois pontos geradores de insegurança para as gestantes foram a possibilidade de não ter a companhia de pessoas conhecidas durante o trabalho de parto (o que implicaria em ficar sozinhas com a equipe do hospital no momento do nascimento do bebê) e a incerteza da internação no momento em que chegassem ao hospital, com chance de serem mandadas de volta para casa. Os relatos de $\mathrm{P} 16$ e $\mathrm{P} 11$ tratam, respectivamente, dessas situações: "Ou então de você chegar no hospital e falar que não é a hora, e você voltar... 
Porque acontece muito isso, né: 'não, você tá sentindo dor, mas é assim mesmo, é normal", (P11).

Ah, eu penso assim de... de ficar lá sozinha, só os médicos comigo. Porque assim, às vezes, quando é no particular, outra pessoa pode participar do seu parto. Mas quando é no hospital público, aí não pode, outra pessoa não pode participar junto com você. (P16)

Por fim, ainda na categoria parto como um assunto gerador de insegurança e ansiedade, pode-se destacar os relatos de quatro gestantes, que afirmavam preferir não pensar muito a respeito desse momento, vez que ficavam ainda mais ansiosas e com medo. Preferiam evitar pensar sobre a situação e lidar com ela quando chegasse a hora, em uma postura de evitação no plano cognitivo: "Eu prefiro não pensar, porque eu sou muito ansiosa. Eu prefiro não ficar pensando..." (P1).

A quarta e última categoria do eixo temático expectativas para o momento do parto tratou de perspectivas mais positivas - parto como um momento de felicidade - que incluiu relatos de oito mulheres sobre a possibilidade de ver seu bebê pela primeira vez e "pegar o bebê nos braços", com situações agradáveis, como o nascimento do(a) filho(a). Pôde-se perceber, contudo, que o processo de parturição em si não era o foco, mas somente o meio pelo qual chegariam a ter acesso ao bebê. Duas gestantes relataram que não gostavam de pensar no parto em si, mas nos momentos logo após o nascimento: "Ansiedade demais... eu fico querendo ver o rosto, pegar no colo, amamentar... Ter esse instinto mesmo de mãe, entendeu? A cena? Ah, dele vindo pros meus braços e eu tendo que colocar ele no meu seio pra amamentar" (P15); "Eu acho que a gente fica feliz, também, quando a criança nasce, é um momento muito feliz, sabe?" (P16).

Percebeu-se número maior de expectativas negativas acerca do parto, haja vista as categorias identificadas, que foram ao encontro de aspectos mencionados em pesquisas sobre parto: o parto como momento de dor e sofrimento, com possíveis riscos e complicações; um momento entre vida e morte, gerador de insegurança quanto à capacidade de parir; momento de maus tratos e vergonha, em que se fica sozinha (Dias \& Deslandes, 2006; Jones, 2008; Nascimento, 2011; Parada \& Tonete, 2008). Essas expectativas refletem uma visão do parto como um momento de sofrimento e mal estar, o que pode ocasionar ansiedade e medo nas gestantes à medida que se aproximam do momento do nascimento (Rattner, 2009; Teixeira \& Pereira, 2006).

Nota-se que somente uma categoria referiu-se a situações agradáveis ou prazerosas, indo ao encontro do que tem sido apontado na literatura: o parto muitas vezes ainda é visto predominantemente como algo a ser temido, não associado a possibilidade de sensações agradáveis como prazer, cuidado, carinho, afeto, podendo levar a êxtases e experiências transcendentais. É importante ressaltar que, embora essas associações positivas não sejam popularmente conhecidas, são vivenciadas por muitas mulheres (Davis \& Pascali-Bonaro, 2010). Davis-Floyd (2003) afirma que o desconhecimento das sensações prazerosas e positivas que podem ser sentidas ao longo do trabalho de parto e parto se deve ao grande tabu que ainda envolve a gravidez e o parto. Segundo a autora, na visão da Igreja como instituição, a gravidez é uma evidência concreta da prática sexual (consequência desta) e, dessa forma, deve ser expiada de seu pecado por meio da dor e do sofrimento no parto, conforme sugerem passagens da bíblia. Davis-Floyd relata ainda que as mulheres que passam por experiências de prazer, gozo, êxtase no momento do parto sentem-se envergonhadas e receosas de compartilhar suas experiências, mantendo-as para si. Isso acabaria por favorecer o maior compartilhamento de depoimentos de experiências desagradáveis, levando à impressão de que os momentos de parto e nascimento são naturalmente sofridos.

\section{Sentimento de Preparo e Confiança para o Parto}

Esse eixo temático tratou da percepção e dos sentimentos das gestantes em relação a estarem preparadas e confiantes para o momento do parto. Foram identificadas três categorias: me sinto preparada, estou com medo e relatos contraditórios. A categoria me sinto preparada 
teve menções de cinco gestantes, que afirmaram sentir-se preparadas para o momento do parto: "Tá tranquilo. Eu não tenho dúvida de nada...já me informei... então tá tranquilo também" (P7). A categoria estou com medo foi citada por 10 mulheres que relataram medos e receios relacionados ao parto, não se sentindo suficientemente preparadas, informadas, confiantes para esse momento: "Ah, eu tô um pouco ansiosa, sei lá... nervosa, não sei... Preparada ainda não . . . Não tô confiante não" (P14).

A categoria relatos contraditórios incluiu falas de três mulheres que disseram sentir-se preparadas, mas, ao longo da resposta, expressaram que estavam com medo desse momento, sentindo-se inseguras e tendo ainda muitas dúvidas: "Sinto [preparada]. Inclusive eu tô bem tranquila. Eu só tenho... às vezes eu me sinto meio insegura, assim, com medo, por conta da dor, né? Eu fico imaginando... Mas, é tentar..." (P4).

Esse eixo temático trouxe informações relevantes, já que poucas gestantes relataram sentir-se preparadas para o momento do parto. As sensações de medo, apreensão e sentimentos de não estarem confiantes para esse momento predominaram entre as entrevistadas. Relacionando essas informações com os eixos o parto como tema no pré-natal e expectativas para o momento do parto, apreende-se que a maioria das gestantes, apesar da proximidade da data do parto, ainda não se sentia preparada e confiante para tal vivência. É possível hipotetizar que esses sentimentos e percepções podem decorrer do fato de não terem conversado e recebido informações suficientes sobre o assunto, e também por terem, em geral, expectativas negativas acerca desse momento, o que leva a um questionamento de suas capacidades para lidar com situação aparentemente tão aversiva, segundo seus relatos acerca das expectativas em relação ao parto. Não surpreende, portanto, que alguns autores como Almeida et al. (2012), Rattner (2009) e Rodrigues e Siqueira (2008) atribuam o aumento da taxa de cesáreas a uma "cultura da cesárea" propagada por profissionais de saúde e mesmo por usuárias - que promete "livrar" a mulher de contexto ansiogênico e estressante.

\section{Contribuições do Serviço na Preparação da Gestante para o Parto}

Esse eixo temático buscou explorar se haveria, de acordo com a opinião das gestantes, ações que poderiam ser feitas no serviço pré-natal, para que se sentissem mais preparadas e confiantes para o momento do parto. Foram identificadas duas categorias: o pré-natal não pode ajudar e me sentiria mais preparada se... A primeira delas - o pré-natal não pode ajudar - com 10 menções, incluiu relatos de gestantes que afirmaram que não havia nada que pudesse ser feito no atendimento pré-natal para que se sentissem mais confiantes e preparadas. Foi opinião frequente que ações para se sentirem mais preparadas eram de responsabilidade delas próprias e da família.

Não sei. Só assim, mais o apoio da minha família, da família dele [marido], acho que só. . . . Acho que, você estando tranquila com você mesma, poderia também dar certo né? . . você poder passar a gravidez toda tranquila sem problemas emocionais, entendeu? (P15)

A segunda categoria - me sentiria mais preparada se...- obteve oito relatos de gestantes, trazendo sugestões de mudanças ou de realização de ações no atendimento pré-natal que acreditavam poder melhorar sua confiança e seu preparo para o parto. Elas referiram que iriam sentir-se mais preparadas se: (a) fornecessem mais informações sobre o momento do parto; (b) os profissionais dessem atenção mais individualizada, apoiando-as em suas necessidades particulares relacionadas ao parto; (c) o centro de saúde realizasse mais palestras sobre temas relacionados ao parto; (d) houvesse preparação psicológica para o momento do parto; (e) o parto fosse realizado com o mesmo médico(a) que acompanhou a gestante ao longo do pré-natal. $\mathrm{O}$ relato a seguir exemplifica algumas opiniões: "Um apoio maior, bem maior... pra gestante. Acho que é um momento muito importante pra gestante pra ficar... tudo meio vago, assim, né? Informar bem a pessoa, conversar, acalmar, mostrar desenhos, talvez, acho que falta muito isso" (P6). Cabe ressaltar que a necessidade de obtenção de informações sobre suas dúvidas e 
demandas sugere que poderia haver déficit na transmissão efetiva e adequada das informações necessárias no serviço, como já apontado anteriormente (Mabuchi \& Fustinoni, 2008).

$\mathrm{Na}$ distribuição dos relatos nas categorias do eixo contribuições do serviço na preparação da gestante para o parto, quase a metade das participantes relatou que não havia nada que pudesse ser feito no atendimento pré-natal para que se sentissem mais confiantes e preparadas. Esse fato permite pensar na hipótese de que o pré-natal não estava sendo visto como um espaço de auxílio às gestantes no que se refere ao apoio e ao fornecimento de informações, mas apenas como um acompanhamento das questões fisiológicas relacionadas à mulher e ao bebê (Domingues et al., 2004). Parte dessas mulheres atribuiu a si a responsabilidade de sentir-se preparada e confiante para o parto, parecendo haver a ideia de que essa deve ser uma capacidade adquirida pela mulher ao longo da gestação, e não um processo de construção coletiva e compartilhamento de responsabilidades, incluindo diferentes atores, como familiares e profissionais de saúde.

\section{Considerações Finais}

Os resultados desse estudo reafirmam o quanto a gestação merece especial atenção para uma adequada preparação ao longo do período pré-natal. Dentre os dados que mais chamaram atenção, pode-se apontar a percepção das gestantes sobre o seu preparo para o parto, considerado insuficiente pela maioria delas. Observou-se ainda clara preferência das mulheres por parto normal/vaginal e, ao mesmo tempo, grande quantidade de relatos de inseguranças e medos referentes ao momento do parto. Assim, considera-se urgente a necessidade de que a preparação para o parto se torne foco nos atendimentos e serviços oferecidos no pré-natal, bem como nas políticas públicas voltadas para essa área, a fim de evitar os efeitos prejudiciais que o estresse, a insegurança, o medo e outros fatores psicoemocionais e ambientais possam ter nos momentos de trabalho de parto e parto.

Destaca-se que hoje há claro esforço do Ministério da Saúde e de instituições associadas para reduzir a taxa de cesáreas no Brasil. Campanhas de incentivo ao parto normal e modificações em diversos aspectos dos serviços de saúde têm sido feitas na tentativa de contribuir para o aumento do número de partos normais e redução na ocorrência de partos cirúrgicos. No entanto, pouco se tem falado sobre a preparação das mulheres ao longo da gestação para que tenham condições físicas, psicológicas e emocionais adequadas para esse momento. Assim, sugere-se maior oferta de apoio psicoemocional, informações e práticas que visem preparar a gestante e seu acompanhante para o parto ao longo do acompanhamento pré-natal.

É importante destacar algumas limitações do estudo, assim como possibilidades para pesquisas futuras. $\mathrm{O}$ estudo foi realizado em apenas duas unidades de saúde de Brasília/DF, o que restringe a análise da assistência pré-natal oferecida de modo geral, considerando que há realidades bastante diferentes nos centros de saúde. Assim, sugere-se que outras pesquisas envolvam mais unidades de saúde, contemplando diferentes realidades. Outro aspecto de destaque é que foram entrevistadas somente gestantes que faziam acompanhamento pré-natal na rede pública de saúde. No entanto, é importante considerar também gestantes que fazem pré-natal em serviços privados, vez que as realidades das duas modalidades de serviços costumam ser consideravelmente diferentes. Além disso, é no âmbito da rede particular de saúde que se dá a maior parte das cesarianas, o que torna fundamental investigar como vem sendo feita a preparação dessas gestantes para o parto, bem como suas expectativas para esse momento.

Um terceiro aspecto de limitação da pesquisa foi que as gestantes entrevistadas eram todas primigestas, o que pode ter contribuído para uma percepção aumentada de alguns aspectos, como inseguranças, receios, preocupações, tipicamente comuns na primeira gestação. Assim, faz-se a sugestão de estudos comparativos com gestantes multigestas para verificar suas dificuldades, expectativas e sua percepção de preparo para o parto.

Recomendam-se, ainda, estudos de caráter epidemiológico, para que se obtenha panorama 
mais acurado sobre a percepção de gestantes acerca da preparação para o parto, suas expectativas e seus sentimentos quanto ao preparo para o parto. Dessa forma, ao compreender melhor a realidade do pré-natal e do parto, pode ser possível melhorar sua qualidade, tanto no âmbito das vivências das mulheres e casais gestantes, quanto no âmbito da saúde pública e das recomendações do Programa de Humanização do Pré-natal e Nascimento.

\section{Referências}

Almeida, N. A. M., Medeiros, M., \& Souza, M. R. (2012). Perspectivas de dor do parto normal de primigestas no período pré-natal. Texto Contexto Enfermagem, 21(4), 819-827. doi:10.1590/ S0104-07072012000400012

Bardin, L. (2011). Análise de conteúdo. São Paulo, SP: Edições 70.

Basso, J. F., \& Monticelli, M. (2010). Expectativas de participação de gestantes e acompanhantes para o parto humanizado. Revista Latino-Americana de Enfermagem, 18(3), 97-105. doi:10.1590/ S0104-11692010000300014

Bortoletti, F. F. (2007). Psicodinâmica do ciclo gravídico puerperal. In F. F. Bortoletti, A. F. Moron, J. Bortoletti Filho, M. U. Nakamura, R. M. Santana, \& R. Mattar (Eds.), Psicologia na prática obstétrica: Abordagem interdisciplinar (pp. 2131). Barueri, SP: Manole.

Davis, E., \& Pascali-Bonaro, D. (2010). Orgasmic birth: Your guide to a safe, satisfying and pleasurable birth experience. New York: Rodale.

Davis-Floyd, R. (2003). Birth as an American rite of passage. Los Angeles, CA: University of California Press.

Dias, M. A. B., \& Deslandes, S. F. (2006). Expectativas sobre a assistência ao parto de mulheres usuárias de uma maternidade pública do Rio de Janeiro, Brasil: Os desafios de uma política de humanização da assistência. Cadernos de Saúde Pública, 22(12), 2647-2655. doi:10.1590/ S0102-311X2006001200014

Domingues, R. M. S. M., Santos, E. M., \& Leal, M. C. (2004). Aspectos da satisfação das mulheres com a assistência ao parto: Contribuição para o debate. Cadernos de Saúde Pública, 20(Supl. 1), S52-S62. doi:10.1590/S0102-311X2004000700006

Ferrari, J. (2010). Preferência pela via de parto nas parturientes atendidas em hospital público na cidade de Porto Velho, Rondônia. Revista Brasileira de Saúde Materno-infantil,
10(Supl. 2), S409-S417. doi:10.1590/S151938292010000600020

Haddad, S. E. M. T., \& Cecatti, J. G. (2011). Estratégias dirigidas aos profissionais para a redução das cesáreas desnecessárias no Brasil. Revista Brasileira de Ginecologia e Obstetrícia, 33(5), 252-262. doi:10.1590/S010072032011000500008

Hodnett, E. D., Gates, S., Hofmeyr, G. J., \& Skala, C. (2007). Continuous support for women during childbirth [Intervention review]. Cochrane Database of Systematic Reviews 2011, 2. Art. No.: CD003766. doi:10.1002/14651858. CD003766.pub3

Instituto Brasileiro de Geografia e Estatística. (2009). Nascimentos no Brasil: $O$ que dizem as informações? Recuperado em http://www.ibge.gov. $\mathrm{br} /$ home/estatistica/populacao/indic_sociosaude /2009/com_nasc.pdf

Jones, R. H. (2008). Memórias do homem de vidro: Reminiscências de um obstetra humanista. Porto Alegre, RS: Idéias a Granel.

Mabuchi, A. S., \& Fustinoni, S. M. (2008). The meaning given by the healthcare professional to labor and humanizing delivery. Acta Paulista de Enfermagem, 21(3), 420-426. doi:10.1590/ S0103-21002008000300006

Ministério da Saúde. (2000). Portaria 569. Programa de Humanização do Pré-Natal e Nascimento. Brasília, DF: Autor. Recuperado em http:// sisprenatal.datasus.gov.br/SISPRENATAL/ Portaria_569_GM.pdf

Ministério da Saúde. (2001). Parto, aborto e puerpério: Assistência humanizada à mulher. Brasília, DF: Autor. Recuperado em http://portal.saude. gov.br/portal/arquivos/pdf/parto_aborto_puerperio.pdf

Ministério da Saúde. (2006). Pré-natal e puerpério: Atenção qualificada e humanizada. Manual técnico. Direitos Sexuais e Direitos Reprodutivos: Caderno $n^{\circ}$ 5. Brasília, DF: Autor.

Nagahama, E. E. I., \& Santiago, S. M. (2008). Práticas de atenção ao parto e os desafios para humanização do cuidado em dois hospitais vinculados ao SUS em município da região sul do Brasil. Cadernos de Saúde Pública, 24(8), 1859-1868. doi:10.1590/S0102-311X2008000800014

Nascimento, N. M. (2011). A contribuição das tecnologias não-invasivas de cuidado de enfermagem para o empoderamento feminino na gravidez e no parto: Adaptação do modelo de promoção da saúde de Nola Pender (Dissertação de mestrado, Universidade Estadual do Rio de Janeiro, RJ, Brasil). 
Odent, M. (2002). A cientificação do amor. Florianopolis, SC: Saint Germain.

Organização Mundial de Saúde. (2015, abr.). Declaração da OMS sobre Taxas de Cesáreas. Recuperado em http://www.unasus.gov.br/noticia/ declaracao-da-oms-sobre-taxas-de-cesareas

Parada, C. M. G. L., \& Tonete, V. L. P. (2008). O cuidado em saúde no ciclo gravídico-puerperal sob a perspectiva de usuárias de serviços públicos. Interface: Comunicação, Saúde, Educação, 12(24), 35-46. doi:10.1590/S141432832008000100004

Pinheiro, B. C., \& Bittar, C. M. L. (2013). Expectativas, percepções e experiências sobre o parto normal: Relato de um grupo de mulheres. Fractal Revista de Psicologia, 25(3), 585-602. doi:10.1590/S1984-02922013000300011

Rattner, D. (2005). Reflexões sobre qualidade e humanização. In D. Rattner \& B. Trench (Eds.), Humanizando nascimentos e partos (pp. 23-32). São Paulo, SP: Editora do Serviço Nacional de Aprendizagem Comercial.

Rattner, D. (2009). Humanização na atenção a nascimentos e partos: Breve referencial teórico. Interface: Comunicação, Saúde, Educação, 13(Supl. 1), 595-602. doi:10.1590/ S1414-32832009000500011

Rodrigues, A. V., \& Siqueira, A. A. F. (2008). Sobre as dores e temores do parto: Dimensões de uma escuta. Revista Brasileira de Saúde Materno Infantil, 8(2), 179-186. doi:10.1590/S1519. 38292008000200005

Santos-Neto, E. T., Alves, K. C. G., Zorzal, M., \& Lima, R. C. D. (2008). Políticas de saúde materna no Brasil: Os nexos com indicadores de saúde materno-infantil. Saúde e Sociedade, 17(2), 107119. doi:10.1590/S0104-12902008000200011
Seibert, S. L., Gomes, M. L., \& Vargens, O. M. C. (2008). Assistência pré-natal da casa de parto do Rio de Janeiro: A visão de suas usuárias. Escola Anna Nery Revista de Enfermagem, 12(4), 758764. doi:10.1590/S1414-81452008000400021

Silva, L. M., Barbieri, M., \& Fustinoni, S. M. (2011). Vivenciando a experiência da parturição em um modelo assistencial humanizado. Revista Brasileira de Enfermagem, 64(1), 60-65. doi:10.1590/ S0034-71672011000100009

Teixeira, N. Z., \& Pereira, W. R. (2006). Parto hospitalar - Experiências de mulheres da periferia de Cuiabá - MT. Revista Brasileira de Enfermagem, 59(6), 740-744. doi:10.1590/S003471672006000600004

Tornquist, C. S. (2003). Paradoxos da humanização em uma maternidade no Brasil. Cadernos de Saúde Pública, 19(Supl. 2), S419-S427. doi:10.1590/S0102-311X2003000800023

Vieira, S. M., Bock, L. F., Zocche, D. A., \& Pessota, C. U. (2011). Percepção das puérperas sobre a assistência prestada pela equipe de saúde no pré-natal [Número especial]. Texto e Contexto Enfermagem, 20, 255-262. doi:10.1590/S010407072011000500032

World Health Organization. (1985). Appropriate technology for birth. Lancet, 2, 436-437. doi:10.1016/S0140-6736(85)92750-3

World Health Organization. (1996). Care in normal birth: A practical guide. Geneva, Switzerland: Author. 